\title{
3D scanning applications in medical field: A literature-based review
}

\author{
Abid Haleem, Mohd. Javaid* \\ Department of Mechanical Engineering Jamia Millia Islamia, New Delhi, India
}

\section{A R T I C L E I N F O}

\section{Keywords:}

3D scanning

3D printing

Applications

Medical image

Medical models

Medical advancements

\begin{abstract}
A B S T R A C T
Background: Medical field has extensive use of different scanning like X-rays, CT, MRI and Ultrasound. These techniques are quite useful for providing information on the internal organs. However, there is a gap for obtaining information of the outer body parts which can now be taken care by 3D Scanning technologies. A large number of research papers about different scanning techniques and 3D scanning has been studied to identify the impact of them and the subsequent research.

The aim of the work: Doctors and technologists use the available scanning technologies in different sub-medical fields. This paper endeavours to find out the best possible usage of 3D scanning technologies in the medical area. This paper will help doctors for best treatment to the patient with high knowledge, minimum risks and maximising benefits.

Materials and methods: A large number of the relevant research papers from 2008 to April 2018, identified through Scopus are studied using bibliometric analysis, thus to determine strength \& limitation and to undertake application analysis.

Results: Year-wise, Journal-wise and relevant applications wise study undertaken in the medical field through Bibliometric research to identify the strength, limitations, and applications of 3D scanning, and other contemporaries scanning technologies.

Conclusion: The bibliometric analysis shows that there is an increasing trend in the research work undertaken in 3D scanning application in the medical field, this also explains future potential and contribution. Corporate are exploring 3D scanning for commercial medical applications along with part analysis \& designs before the actual production. It helps to create efficient implants easily and quickly. In this paper, we have summarised 3D scanning applications for medical purposes. This technology helps to produce medical implant according to the required specification. It is used for the accurate measuring of patient's body shape, size and skin surface area or an individual part of the body. In medical, data varies from patient to patient, so for producing a 3D digital image, 3D scanning technologies are used which provide digital 3D models. We can obtain improved patient treatment through the integration of digital models with Virtual Reality and Holographic techniques. The significant limitation of this technology is that it can only scan the outer surface of the body or part/model.
\end{abstract}

\section{Introduction}

Medical practitioners traditionally measure body shape and size by hand or specific devices to diagnose and decide treatment/health status. Contemporarily for producing 3D internal images of a patient body, X-rays, computed-tomography, (CT) scanners, Ultrasound and Magnetic resonance imaging (MRI) are commonly used. With the advent of 3D scanners, which are safe and convenient to use to measure a person's body shape, size, texture, colour and skin-surface area accurately, a new clinical application area is emerging, i.e. 3D Scanning has a high capability of capturing 3D measurement without physical contact. $^{1,2}$

3D scanners capture an accurate part image in a three-dimensional format in few seconds. This digital data generated is compatible with available designing, testing and inspection software. This technology uses software that automatically extracts measurement during scanning and eliminates transcription and measurement errors. Advance technologies enabled diagnostic studies in recent years reveal detailed information about the internal structure of the body. ${ }^{1}$ Computed-tomography (CT), magnetic resonance imaging (MRI), X-rays and ultrasound provides a platform to study anatomy and physiology aid in the diagnosis and disease monitoring. ${ }^{3,4}$

From last three years, 3D scanning and printing technologies applications have increased approximately more than ten times. Design prototype of the new or modified product or an architectural model of buildings are made, and today 3D printer machines itself are printing

\footnotetext{
* Corresponding author.

E-mail addresses: ahaleem@jmi.ac.in (A. Haleem), mjavaid@jmi.ac.in (M. Javaid).
} 
3D printer. Bioprinting, food, implants and even real house printing is done. $3 \mathrm{D}$ scanner is used to capture the object shape in digital form and manufactured prototype with the support of AM system. ${ }^{5,6}$ As compared to the traditional scanning method, it is less invasive that reduces stress and discomfort. Through the improved assessment, it reduces product waste and also improves quality ${ }^{7,8}$

The 3D scanner can facilitate rapid creation of implants and eliminate manual measuring process. In 3D scanners, point cloud data is helpful for designing of suitable customised applications like gloves, body shape, implants, prosthetics and anatomical models surface texture, restoring shape and colour safely., ${ }^{9,10}$

The digital data can also use for the creation of holograms and can be used for applications requiring human body imaging such as medical, garment creation, sports performance, and security. ${ }^{11,12}$

This technology can be used for detecting scoliosis patient's back shape. The evaluation of cosmetic product effect is also possible with the aid of 3D scanning technology. It can perform scanning of human feet to detect anomalies. ${ }^{13,14}$ For the designing of custom clothing, 3D scanning technologies are also useful. ${ }^{15,16}$ In medical engineering, 3D scanning is utilised to scan body structures for replication and characterisation. ${ }^{17,18}$

At disease diagnosis level, 3D modelling can be used for the estimation of bleeding in haemophilia, lung function and abdominal-shape characteristics; thus we can measure several parameters such as distances, surface area, volume and surface area. ${ }^{19,20}$

The high-quality data captured by the scanner is used in surveying field, medical and manufacturing industries. The application of this technology is also in the 3D documentation of historical and cultural landmarks. ${ }^{21}$ Any objects can be quickly copied in 3D and viewed from any view/angle. ${ }^{22,23,24}$

The principle of $3 \mathrm{D}$ scanning device is similar to that of a camera, where many images are combined to construct a virtual 3D model. For creating $3 \mathrm{D}$ images, three main technologies are used, i. e. photogrammetry, stereo vision, and fringe projection. For making a 3D digital file, it combines multiple images to reconstruct a representation. For monitoring longitudinal changes in body morphology, 3D scanning is useful; such longitudinal changes happen due to exercise and nutrition or through attendance at a gymnasium. ${ }^{25}$

\section{Differentiating x-ray, computed-tomography (CT) scanners, magnetic resonance imaging (MRI), ultrasound and 3D scanning}

Various technologies are being developed and are used to obtain data from the patient body or instruments or models. The first technologies being used to scan the human being are discussed in the following subsections.

\subsection{X-rays}

$\mathrm{X}$-rays are used to produce a medical image in a way that soft tissue such as organs, skin that cannot absorb high-energy rays, and pass beams through them. However dense materials like bones absorb the radiation and status of bone are captured through the X-rays. Like a camera, X-rays are also developed on X-rays films depending upon the exposure area. It is also used by dentists to diagnose and used for a broad variety treatment. X-ray is a type of light ray, i.e. like a visible light which we see every day. The main difference between X-rays and visible light is that X-rays have different wavelength. ${ }^{22,26}$

\subsection{CT scan}

A CT scan sends X-ray beam to the body that moves through an arc and captures many pictures. CT scan sees tissue inside a solid organ and different level of density. It provides detail information about the body such as brain and its vessels, inner ear, eyes, sinuses, heart, lungs, neck, spine, shoulder, reproductive system and another inner part of the body with a high-resolution image. ${ }^{27,28,29}$

\subsection{MRI scan}

MRI uses powerful magnetic field and radio frequency pulses to achieve the detailed picture of bone, soft tissues, organs and other internal structure of the body. MRI differentiates normal and abnormal tissue. It helps to obtain an accurate diagnosis. ${ }^{30,31}$

\subsection{Ultrasound}

Ultrasound produces inside pictures of the body by using sound waves. It helps to diagnose the cause of swelling, pain and infections in the internal organs of the body. It is used to help diagnose heart conditions, guide biopsies and assess damage after a heart attack. Ultrasound is non-invasive, safe and does not use any ionising radiation. Ultrasound imaging is also known as sonography or ultrasound scanning. ${ }^{32}$

\subsection{Dimensional scanning}

3D scanning is used to create free-form three-dimensional data in the form of a point cloud or a triangle mesh. Image/scans data is formatted into a standard reference system, where they are merged to form a complete model called alignment. Capture the image with the help of structured light in a 3D form where series of light patterns cast by the projector on an object, while the camera captures an image of the object. ${ }^{33,34}$

A comparative analysis of different Scanning technologies is necessary before making an exhaustive study of 3D Scanning. Table 1 elaborates the strength, weaknesses and applications of, X-rays, CT, MRI, Ultrasound and 3D scanning.

The difference between 3D scanning with X-rays, CT scan, MRI scan \& Ultrasound is that scanning through 3D Scanning provides information about the outer surface of the body whereas scanning by X-rays, ultrasound, CT, MRI ultrasound technologies provide internal geometry of the body part, like bone, tissues and different organs. All these technologies are used for different requirements in medical imaging which helps to establish the diagnosis of various diseases and problems.

\section{Expanding medical applications through 3D scanning}

3D scanning has a revolutionising effect on many industries, and same is being observed in the medical sector. Some of the researcher already saying this technology is helpful in the printing of human bone and help in transplantation. ${ }^{15,35}$

This technology successfully helps to create parts like prosthetics, dental appliances, custom implant, prosthetic limbs by using 3D printing technologies which look and feel like a real thing. ${ }^{36,37} 3 \mathrm{D}$ objects can be easily produced from a printer, which takes inputs from 3 D scanner through a 3D digital file. The service of 3D scanning is just as crucial to the medical field as crucial it is to the printer. ${ }^{38,39}$ 3D scanner \& printer have already produced kidney cells that are acting like a real. One of the critical impacts of this technology is in the pharmaceutical industry. By using 3D scanning instrument, anyone will get directly what organ he or she requires, and a large number of patients will be saved.

\subsection{Research status on $3 D$ scanning application in medical Field}

\subsubsection{Research status of $3 D$ scanning through a bibliometric study}

Extensive research is being undertaken in the area of 3D scanning technologies. Scopus database is used to identify the research articles in the area of 3D Scanning application; here we identified 2507 articles till April 2018 belonging to the area. The first paper on 3D scanning was published in 1982. In 2008, we observed that 123 research articles 


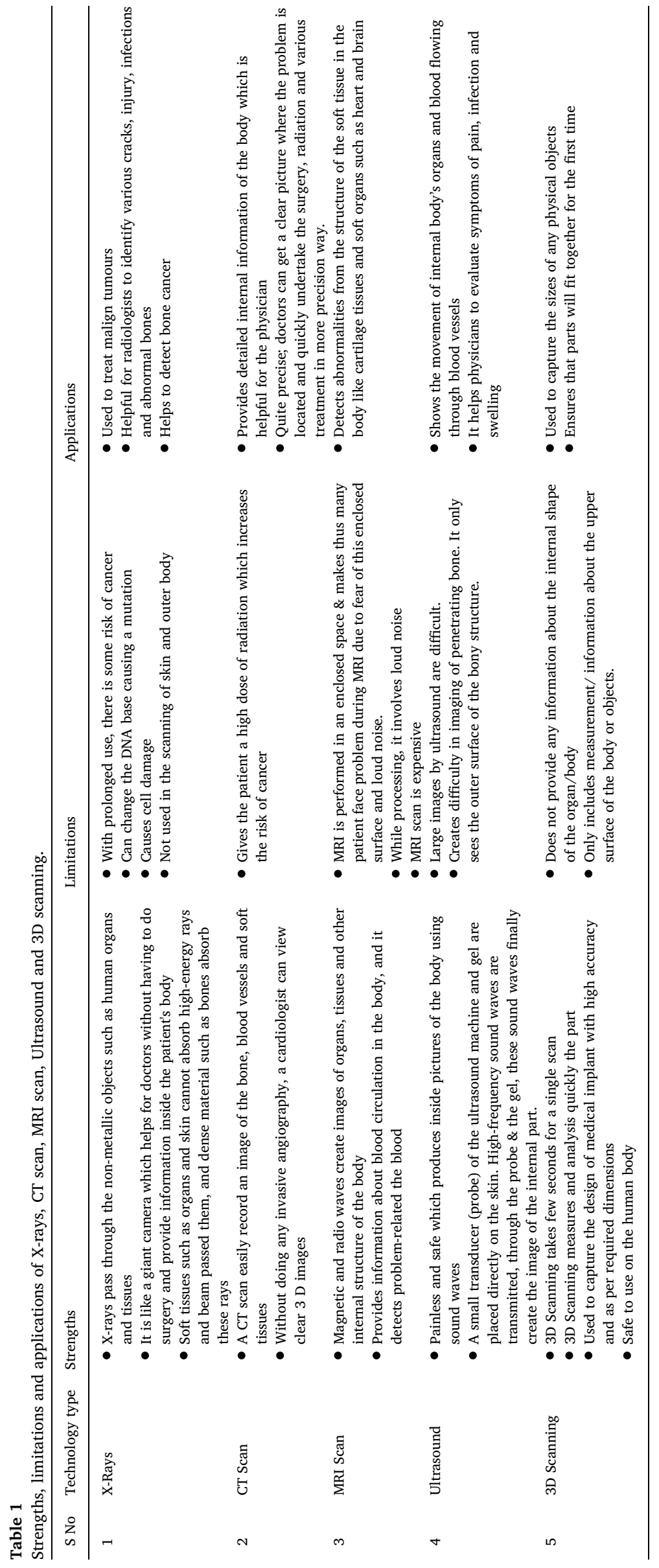




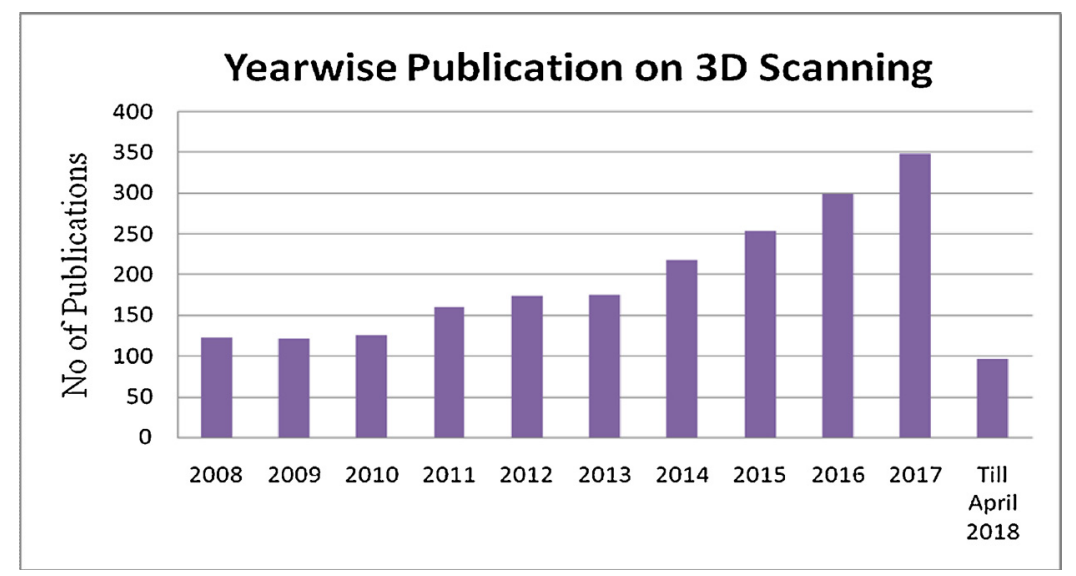

Fig. 1. 3 D scanning: Year-wise publications (Source: Scopus).

published on this technology, and it increased to 349 in 2017, and till may 2018, 96 articles are published in this area. Fig. 1 shows, year-wise publication on 3D scanning from 2008 to April 2018.

There is a sustained increase in some articles related to 3D scanning. The details of the papers published in different journals on 3D scanning are shown in Fig. 2; this also shows the top five journals in this area Out of top five, Applied Mechanics and the Material Journal have highest publications of 36 . Advanced materials research has 27 publication is at position 2. ACM Transaction Journal published 21 papers and is ranked third. International Journal of Advance Manufacturing Technology is at the fourth place, and Key Engineering Materials Journal published twelve articles and is at fifth rank. One can quickly identify that top contributes in the area of 3D scanning are from the material and manufacturing sector.

Fig. 3 shows the area wise research on 3 D Scanning; we observe that 22 percent scanning papers are in the field of engineering whereas computer science contribution is $22 \%$, and medical field contributes only $6 \%$. It has diverse applications in other areas of Physics and Astronomy, material science, mathematics, medicine, social science and others.

\subsubsection{Research status on $3 \mathrm{D}$ scanning in the medical field}

The medical field is increasingly focusing on $3 \mathrm{D}$ Scanning related publications. As evident from Scopus data, the researcher from the medical field has been growing and published a total of 153 research articles until April 2018. The first paper on $3 \mathrm{D}$ Scanning was published in 1982; however, its application in the medical field was reported in 1994 thus, showing a lag of 12 years. As evident from year wise publication from 2008 to April 2018, there is a continuous improvement in the publications in this area. In the year 2008, there were nine research articles published, and it improved to 35 in 2017. Till April 2018 five articles are published in 3D scanning in the medical area. (Please see Fig. 4)

The top five Journals that published articles on 3D Scanning in Medical field is shown in Fig. 5.

Fig. 6 shows a pie chart the area-wise research reported on $3 \mathrm{D}$ Scanning in the Medical Field. Here, the maximum contribution is from the engineering field (24\%), and implementation of 3D scanning in the medical area is $18 \%$.

From Scopus data, we analysed, that applications of 3 D scanning technology are increasing in every area. Thus, accordingly, the 3D scanning technologies/machines are also maturing and becoming commercially viable and therefore acceptable in the field of medical applications.

\subsection{Various requirements for medical field}

The focus of the medical field is to create a complex medical model in lesser time with lower cost, along with achieving an accurate result, lightweight implant, reduction of operating time, reconstruction of a skull and improve quality of implant. After studying the major research papers, the requirements of the medical field are classified into five major areas. 3D scanning technologies help to fulfil these medical field requirements.

\subsubsection{Complexity}

Traditional manufacturing technologies are not conformable in febricity complex and organic shapes of the outer part of the body. It

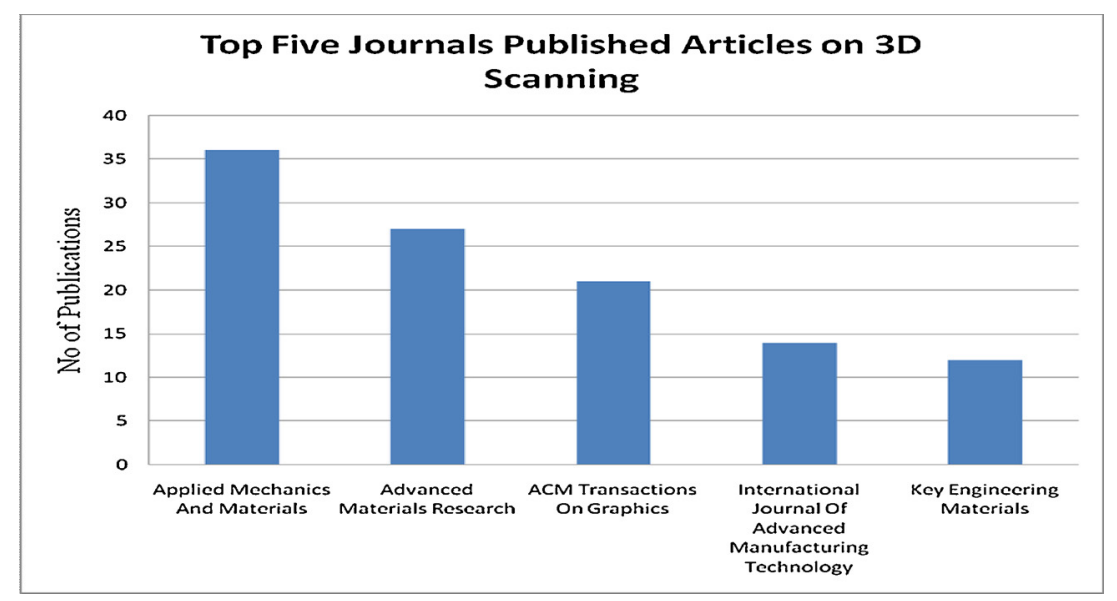

Fig. 2. 3 D Scanning: Top five Journals (Source: Scopus). 


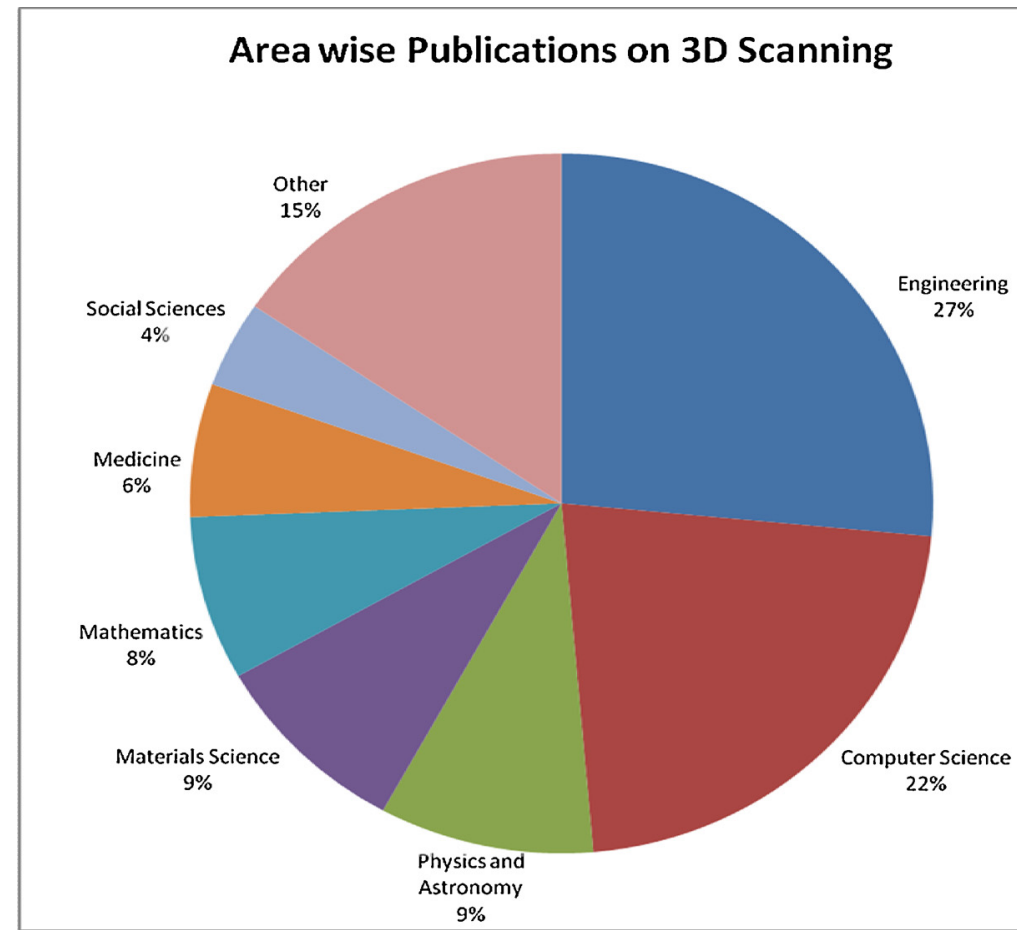

Fig. 3. 3 D Scanning: Area-wise contribution (Source: Scopus).

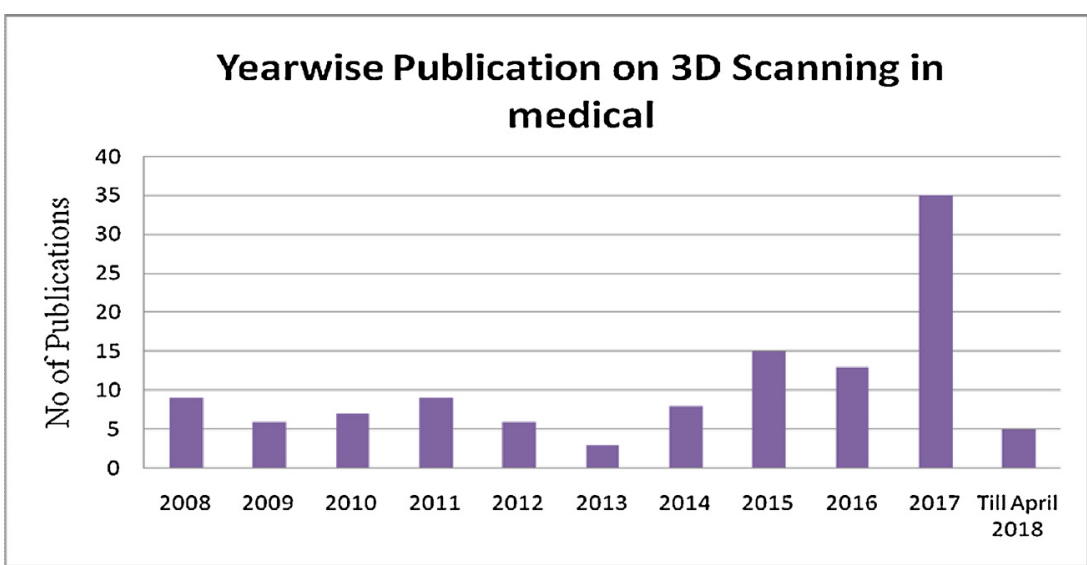

Fig. 4. 3 D scanning in Medical field: Year-wise publications (Source: Scopus).

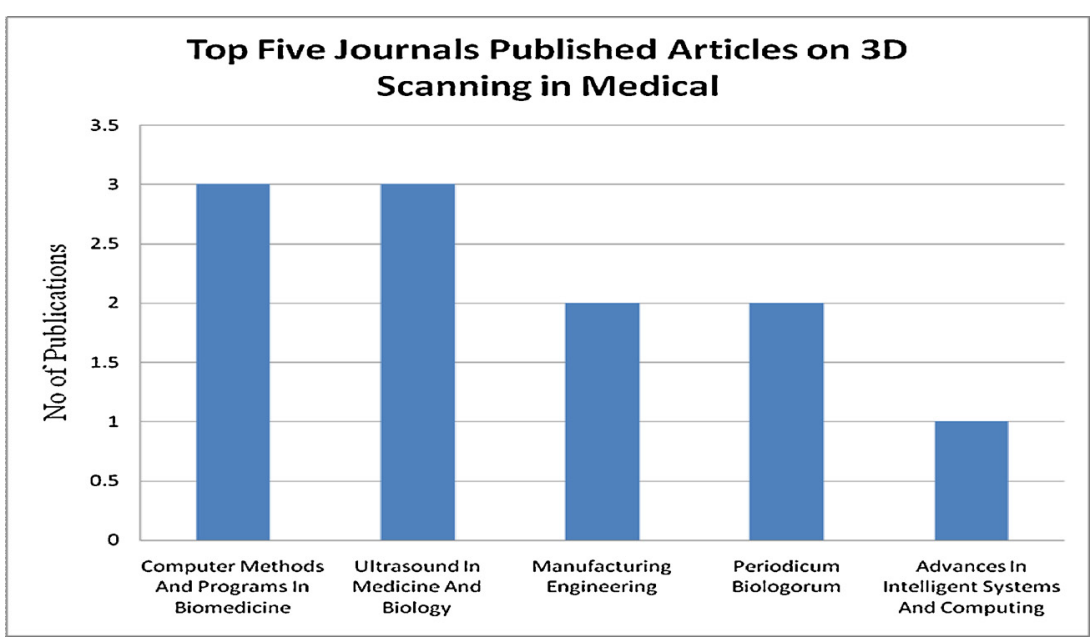

Fig. 5. 3 D Scanning in Medical field: top five Journals (Source: Scopus). 


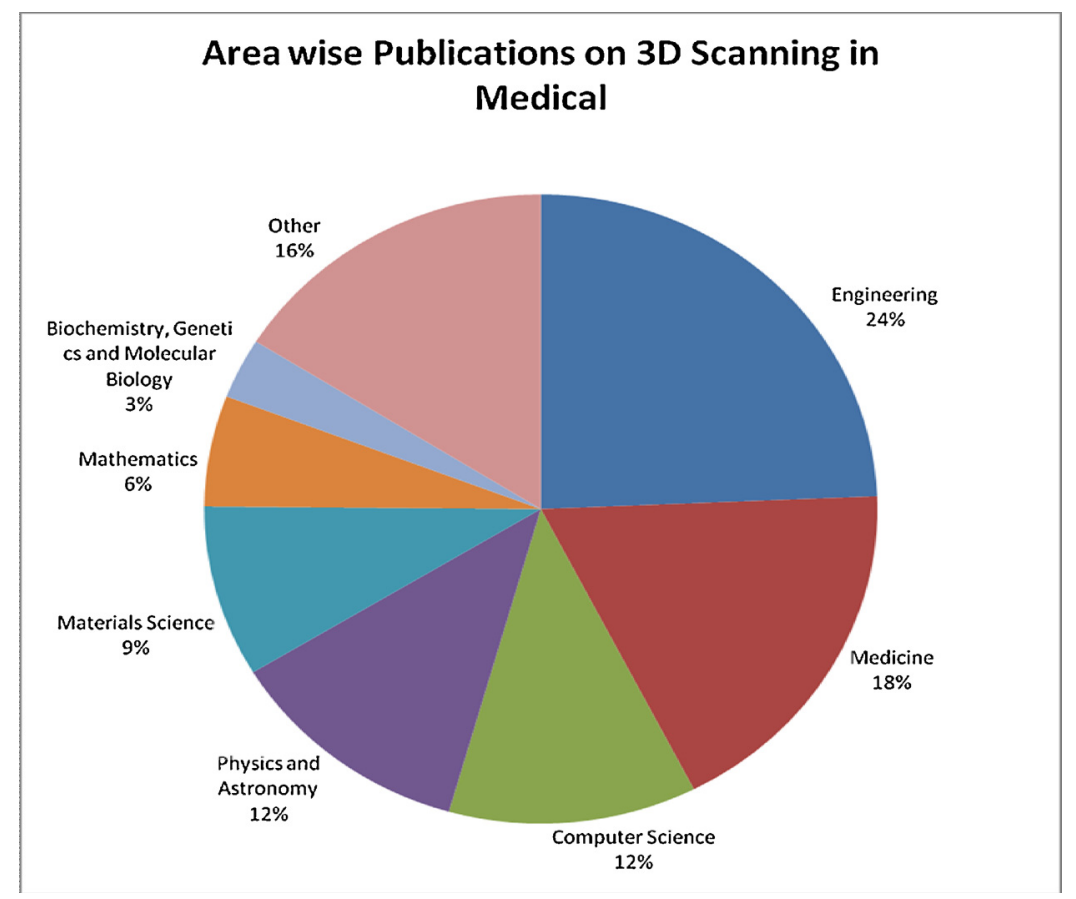

Fig. 6. 3 D Scanning applications in Medical field: Area-wise contribution Source: Scopus).

Table 2

Contemporary criteria's of 3D scanners usage in medical applications.

\begin{tabular}{|c|c|c|c|}
\hline S.No & Criteria's & Description & References \\
\hline 1 & High accuracy & $\begin{array}{l}\text { - Accuracy is an important parameter, which helps to identify changes in the human body during } \\
\text { scanning } \\
\text { - These changes are caused by oedemas, muscle strengthening or muscle atrophy } \\
\text { - Doctors can now achieve an accurate model of the patient implant } \\
\text { - Make exact scan replica of the 3D model, and this helps in treatments and surgery } \\
\text { - As compared to the conventional 2D realm of radiography 3D model provides doctors with a } \\
\text { more holistic view and help to achieve an optimal treatment }\end{array}$ & $\begin{array}{l}\text { Chromy and } \text { Zalud }^{25} \text {; } \\
\text { Lerch et al. }^{63}\end{array}$ \\
\hline 2 & High speed & $\begin{array}{l}\text { - The procedure of scanning is fast; scanning shot is taken in few seconds and is highly preferred } \\
\text { instead of measurement } \\
\text { - Scanning of the component can be done with high speed without any risk of damaging the part } \\
\text { - Instead of scanning one point at a time it scans multiple points at once, and it eliminates the } \\
\text { problem of distortion from motion } \\
\text { - 3D scanners are moveable, and body can remain stationary. }\end{array}$ & Groenendyk, and Gallant ${ }^{58}$; Li et al $^{64}$ \\
\hline 3 & Low operational costs & $\begin{array}{l}\text { - Decrease scanning cost, and they are efficient in everyday use } \\
\text { - Use of consumable item is limited to scanning } \\
\text { - 3D scanner, scan product quickly and cheaply } \\
\text { - For customisation in design, it is efficient in medical as well as in manufacturing field }\end{array}$ & Javaid and Haleem $^{65}$; Paquette ${ }^{66}$ \\
\hline 4 & Simple manipulation & $\begin{array}{l}\text { - The device is automated, before each scanning it does not disturb personnel with complex } \\
\text { settings } \\
\text { - Both software and hardware are used to analyse a real-world object which converts the physical } \\
\text { model into a 3D digital file }\end{array}$ & $\begin{array}{l}\text { Hong and Daanen }{ }^{67} \text {; Cynthia and } \\
\text { Hwang }^{68}\end{array}$ \\
\hline 5 & Flexibility & $\begin{array}{l}\text { - 3D scanners have capabilities for scanning the entire body as well as its tiny details } \\
\text { - 3D scanners are flexible, provides flexibility for scanning different shape and size of a product } \\
\text { only simply change its field of view (FOV) } \\
\text { - One can change camera as well as projector according to the requirement } \\
\text { - Flexibility for capturing of various parts such as manufactured products, industrial parts, cultural } \\
\text { artefacts, the dental mould } \\
\text { - This versatile solution is applied in various industries such as arts and entertainment, custom } \\
\text { products, cultural heritage, 3D visualisation of product, reverse engineering, quality inspection } \\
\text { and research. }\end{array}$ & $\begin{array}{l}\text { Lopes et al. }{ }^{69} \text {; McKinnon and } \\
\text { Istook }^{70} \text {; Salleh et al. }{ }^{71}\end{array}$ \\
\hline 6 & $\begin{array}{l}\text { Harmless to patient and } \\
\text { operator }\end{array}$ & $\begin{array}{l}\text { - This technology is not harmful under any circumstances and is quite safe for operating personnel } \\
\text { as well as for the patient } \\
\text { - Excellent solution for capturing object in black and white and also in colour }\end{array}$ & Hong and Daanen ${ }^{67} ;$ Berger $^{72}$ \\
\hline 7 & fewer limitations & $\begin{array}{l}\text { - It is usable for any patient } \\
\text { - According to the health state, it has very low limitations } \\
\text { Easily used for many purposes other than medical fields such as quality control, freeway design, } \\
\text { quality survey, documentation of historical sites, replacing missing or older parts and accident } \\
\text { reconstruction }\end{array}$ & Chromy and Zalud ${ }^{25}$; Cho et al. ${ }^{73}$ \\
\hline 8 & Complex geometries & $\begin{array}{l}\text { - This technology has potential to create the design of complex geometries implant } \\
\text { - Increasingly used in the product design and for part improvement and modification }\end{array}$ & $\begin{array}{l}\text { Dong et al. }{ }^{56} \text {; } \\
\text { Izatt et al. }{ }^{74}\end{array}$ \\
\hline
\end{tabular}


Table 3

Advancement in Medical field by using 3D Scanning.

\begin{tabular}{|c|c|c|c|}
\hline S. No & Advancement & Descriptions & References \\
\hline 1 & Human-body metrics & $\begin{array}{l}\text { - Creates a good impact on research and practice in the field of medicine by which shape \& size with } \\
\text { detailed information would transform the epidemiology of many diseases } \\
\text { - A complex, 3D geometrical scaffolds can be fabricated accurately } \\
\text { - Scanning technologies and 3D printing technologies for customising and creation of 3D models of the } \\
\text { human body } \\
\text { - Capture a highly accurate digital map of our body } \\
\text { - Doctors can solve the problem of building robust and accurate models } \\
\text { - Used to develop either for measurement (the geometry of shape, size, volume and surface area) or } \\
\text { visualisation. }\end{array}$ & Treleaven and wells ${ }^{5}$; Maher et al. ${ }^{76}$ \\
\hline 2 & Skin-surface area & $\begin{array}{l}\text { - It creates an image of the entire body-surface area } \\
\text { approach for the measurement of skin-surface area and optimised applications for precise } \\
\text { measurement of human skin surface area without the need for replicas } \\
\text { - As compared to traditionally body measurement process it saves time and gathers more accurate data }\end{array}$ & Yap et al. ${ }^{77}$; Liu et al. ${ }^{78}$ \\
\hline 3 & Body size and shape & $\begin{array}{l}\text { - The 3D scanner automatically extracts measurements for the state of disease, healthy shape and size } \\
\text { of the body Around a person; it makes a full circle capture body shape and size from all angles and } \\
\text { give a precise measurement } \\
\text { - Generates a virtual 3D model in few seconds which is viewable on a computer screen. 3D models have } \\
\text { colours and texture as the original. It detects things as the human eye cannot do like this. It can also } \\
\text { capture several persons at once including colours and textures. }\end{array}$ & Cynthia and Hwang ${ }^{68}$; Kashani et al. ${ }^{79}$ \\
\hline 4 & $3 \mathrm{D}$ visualisation & $\begin{array}{l}\text { - 3D scanners provide pre visualisation such as clinician-patient interaction in cosmetic surgery } \\
\text { - To assess risk and guide health, clinicians use measurements of the body } \\
\text { - 3D scanner creates visual representations of the body for clinical analysis in short that improve the } \\
\text { diagnostic confidence of the patient and easy to read the solution } \\
\text { - A surgeon can also see the 3D image of anatomy and allow solving the issue } \\
\text { - In visualisation helps to plan for surgery and provide education to the patient } \\
\text { trauma, and transplant surgery }\end{array}$ & $\begin{array}{l}\text { Tukuru et al. }{ }^{54} \text {; } \text { Clark }^{17} \text { Daanen and } \\
\text { Hong }^{16} \text {; Hong et } \mathrm{al}^{80}\end{array}$ \\
\hline
\end{tabular}

takes days or week to complete the process. 3D scanning technologies quickly capture any model. These techniques have potential to scan and print any types of a complex shaped medical model like manufacturing of thin scaffolds is done perfectly. By using 3D scanning technologies, designing of models can be easily done which was not previously possible with other available technologies. ${ }^{1,40}$

\subsubsection{Lead time}

One of the hallmarks of the 3D scanning is quicker design creation and iteration. For a medical device, it is an important tool for achieving success for patients, in less time. It makes the design of the medical tool. We check the 3D design model on the computer before going for fabrication. ${ }^{41,42}$

\subsubsection{Cost}

3D scanner and printers are used to create custom, complex components because medical data is different from patient to patient. It fabricates model at lower cost with machines. By changing the material during printing, it reduces the weight of the part with lesser material waste, which helps in cost reduction. ${ }^{43,44}$

\subsubsection{Data generation}

The 3D scanning produces patient-specific scan data that is easily used with available printers. The data is accurately captured as a collection of points and generates a 3D surface, which is otherwise difficult to measure. The techniques CT, X-rays, ultrasound, laser scanning and MRI can also be used for data generation. ${ }^{45,46,47}$

\subsubsection{Multi-material prints}

Some 3D printing technologies can print 3D physical model using different input materials in a single print. The benefit of this is that it can represent a section of bone. It helps the surgeon to understand the patient-specific problem before developing the model for surgery and is also helpful for educational purpose. ${ }^{48,49,50}$

Next section shows steps used for creating a medical model, thus showing how a model is created through the application of 3D scanning technology.

\section{Steps for creating a medical model through a 3D scanner}

3D Scanning and 3D printing technologies show good potential in several areas including the creation of implants, customised prosthetics, tissue and organ fabrication, pharmaceutical research regarding drug, anatomical models and analysis. For the customisation of a medical product, it is efficient as compared to the traditional methods and it improves productivity. The significant steps followed are as follows:

\subsection{Developing the physical model for scanning/ input}

Input refers to that physical model that is scanned and whose cloud data is obtained. It helps to create a reference model, and sometimes this model is compared with another model, obtained through other CAD processes/scanning process. 3D scanners are used to export image data and additional information in the file format usable in medical field. ${ }^{51,52}$

\section{2. $3 D$ scanning}

This system is fast, accurate and can externally measure different objects. It gives accuracy up to $30 \mu \mathrm{m} .{ }^{53,54}$ The scanned data $\&$ information is converted to standard triangulate language (STL) format. The machine scans outer surface, for diagnostic reasons and same data can use for geometrical structures information. ${ }^{55}$

\subsection{Generating a model for the medical images}

For the generation of an appropriate model of medical images, there is a requirement of computer software for this purpose. The software's used are 3D Slicer, In Vesalius, Mia Lite, 3DIM Viewer, ITK-SNAP, and OsiriX. The body image is sliced into thin cross sections and creates 3D models of the parts by the different software. This software also allows doing some modification in the image. General information provided by the 3D scanner helps radiologists and surgeons to control \& select the correct segmentation of MRI or CT. The segmentation and visualisation data is converted into STL format, which can be used easily with 
Table 4

Medical applications of 3D Scanning.

\begin{tabular}{|c|c|c|c|}
\hline S. No & Applications & Description & References \\
\hline 1 & Medical devices & $\begin{array}{l}\text { - In the Medical industry, 3D scanning is applied just like other organisations } \\
\text { involved in the design and manufacturing areas } \\
\text { - Scan data is used for reverse engineering, part sampling, documentation and } \\
\text { inspection } \\
\text { - Components include tiny, complex electro-mechanical assemblies, catheter-like } \\
\text { devices and large equipment panels } \\
\text { - Plays an essential role in developing medical applications and products } \\
\text { - 3D scanning allows researchers and scientists to gather data from the complex } \\
\text { model which is not possible to measure through traditional devices } \\
\text { - Capture data from the surface of the patient body with good accuracy }\end{array}$ & $\begin{array}{l}\text { Parthasarath }{ }^{82} \text {; Shahbazian et al. }{ }^{83} \text {; Singh and } \\
\text { Singhal }^{84} \text {; Jardini et al. }{ }^{85} \text {; Markl et al. }{ }^{86} \text {; Elsheikh } \\
\text { et al. }{ }^{87}\end{array}$ \\
\hline 2 & Scans patient without contact & $\begin{array}{l}\text { - Without any physical contact with the patient, the body is scanned by the 3D } \\
\text { scanner to ensure that there is not any interference in the measurement } \\
\text { - One of the primary applications is to capture data of the burnt victim in which } \\
\text { direct contact is not permitted } \\
\text { - An accurate scanning of the face is required for maxillofacial surgery } \\
\text { - It is the best 3D solution which is safe, fast and easily operated without any risk } \\
\text { to patient health } \\
\text { - It helps in the manufacturing of medical devices, like custom-made prosthetics, } \\
\text { precise surgical blades and wheelchairs } \\
\text { - It converts the physical product into a digital 3D file and directly provide data } \\
\text { for analysis and manufacturing } \\
\text { - The 3D scanner allows developing a medical solution for the individual patient }\end{array}$ & Hin and $\mathrm{Krul}^{88}$; Chan et al. ${ }^{28}$; Zein et al. ${ }^{89}$ \\
\hline 3 & Diagnosis & $\begin{array}{l}\text { - 3D scanning helps doctors in the diagnosis } \\
\text { It is used to treat skin related problems such as bacterias in the pores, burns and } \\
\text { wrinkles } \\
\text { - With the help of 3D image captured by the 3D scanner, it detects deformities } \\
\text { through the analysis of the patient's body shape. }\end{array}$ & Hsu et al., ${ }^{4549}$; Kashani et al. ${ }^{79}$ \\
\hline 4 & $\begin{array}{l}\text { Implants, Orthotics and } \\
\text { Prosthetics }\end{array}$ & $\begin{array}{l}\text { - Any item that interfaces with or conforms to the patient's anatomy can benefit } \\
\text { from a custom fit } \\
\text { - To deliver implants, dental drill guides and surgical fixtures, which fits the } \\
\text { patients' shape is captured by a 3D scanner with the exact digital match and } \\
\text { create CAD model of the object } \\
\text { - Doctors can practice for operations, surgeries and in preclinical testing } \\
\text { - Doctors can digitise real-world objects and quickly acquire data from broken } \\
\text { anatomy by taking advantages of this technology application } \\
\text { - 3D model scanned by this technology improve communication between doctor } \\
\text { and patient }\end{array}$ & $\begin{array}{l}\text { Lienau et al. }{ }^{90} \text {; Ludlow et al. } .^{91} \text {; Shiraishi et al. }{ }^{92} \text {; } \\
\text { Waran }^{93} \text {; Awasthi et al. } .^{94}\end{array}$ \\
\hline 5 & Monitoring & $\begin{array}{l}\text { - It is a tool which can help a doctor to track the evolution of their patient's body } \\
\text { metrics and allowing diagnosis and recommendations more accurate } \\
\text { - Perfect tool for medical training } \\
\text { - 3D Scanning compliments 3D printing and develops practical solution and } \\
\text { experiments } \\
\text { - By using this non-contact technology, it studies and measure human structure } \\
\text { and enhances training in medical education }\end{array}$ & $\begin{array}{l}\text { Konrad et al. }{ }^{95} \text {; Singh and Singhal }{ }^{96} \\
\text { Wang et al. }{ }^{97} \text {; Koivisto et al. }{ }^{98} \text {; Liang et al. }{ }^{99} \text {; } \\
\text { Awasthi }\end{array}$ \\
\hline 6 & Dentistry & $\begin{array}{l}\text { - In dentistry, 3D scanning is an important tool because plaster model of patient's } \\
\text { mouth or teeth replacement can be built quickly } \\
\text { - Used for treatment planning, diagnosis and appliance construction } \\
\text { - With the help of 3D scanning technique, we recreate a possible best fit model of } \\
\text { the teeth, silicone maxillofacial prosthesis and ceramic crowns }\end{array}$ & Azari and Nikzad ${ }^{50}$; Javaid and Haleem ${ }^{1}$ \\
\hline 7 & Human structures & $\begin{array}{l}\text { - 3D scanning is ideal methods which generate human structure measurements } \\
\text { and exact structure scan } \\
\text { - It plays an essential role in medical and dental areas. It is used to scan spine, } \\
\text { knee, sacrum, femur, tibia, patella, scapula, fibula, shoulder, humerus, clavicle } \\
\text { and hand } \\
\text { - Many of these models contain cartilage, soft tissue, ligaments and arteries. }\end{array}$ & Tawfik et al. ${ }^{29}$; Dawood et al. ${ }^{36}$ \\
\hline 8 & Epidemiology & $\begin{array}{l}\text { For specified population it determinants the health-related states and study of } \\
\text { their distribution } \\
\text { - It is also used for anthropometric surveys and to obtain a meaningful sample for } \\
\text { a study } \\
\text { - It has potential to measure accurate and visualises the body shape size and skin } \\
\text { area } \\
\text { - This technology is more suitable for healthcare applications. }\end{array}$ & Kerens et al. ${ }^{100}$; Dérand et al. ${ }^{47}$ \\
\hline 9 & $\begin{array}{l}\text { Consistent results in time } \\
\text { after time }\end{array}$ & $\begin{array}{l}\text { For different medical practitioners, it generates a repeatable result } \\
\text { There is minimal operator involvement, and the result is consistent in which report } \\
\text { is generated automatically } \\
\text { For quality inspection program it helps to improve the efficiency }\end{array}$ & Yang et al. ${ }^{101}$; Singh et al. ${ }^{102}$; Zhang et al. ${ }^{61}$ \\
\hline 10 & Treatment & $\begin{array}{l}\text { Burn patients are required to be given medicines in the right amount; any } \\
\text { miscalculation can injure the patient } \\
\text { In this case, 3D body scanners or a handheld 3D scanner is precise and accurate } \\
\text { which measure damaged skin surface }\end{array}$ & $\begin{array}{l}\text { Horiguchi }^{103} ; \\
\text { Wells et al. }{ }^{104} \text {; Negi et al. }{ }^{105}\end{array}$ \\
\hline 11 & $\begin{array}{l}\text { Ability to capture 3D } \\
\text { measurements quickly }\end{array}$ & & Ventura et al. ${ }^{106}$; Zein et al. ${ }^{89}$ \\
\hline
\end{tabular}


Table 4 (continued)

\begin{tabular}{|c|c|c|c|}
\hline S. No & Applications & Description & References \\
\hline 12 & Quicker turnaround time & $\begin{array}{l}\text { The single scan is captured in few seconds, and it can immediately analyse the } \\
\text { measurement of the patient in 3D } \\
\text { The process of fast scanning speed also prevents the patient from moving } \\
3 \text { D scanning is safe to use with the human body, as the scanner light is not harmful } \\
\text { to the human skin } \\
\text { It provides a rapid solution and quantifiable process improvement } \\
\text { With high flexibility and process reliability, it gives repeatable, accurate } \\
\text { measurement } \\
\text { Usually, measurement of patient body is derived from the negative impression and } \\
\text { is cast, by using 3D Scanning } \\
\text { This work is done electronically so the measures of patients can be sent online to } \\
\text { different locations and file is sent instantly for production in the laboratory } \\
\text { The process of scanning is easier, faster and significantly reduces the editing process } \\
\text { after scanning } \\
\text { All patient related information can be easily stored }\end{array}$ & $\begin{array}{l}\text { Maher et al. }{ }^{76} \text {; Drury and Mooney }{ }^{53} \text {; Landers } \\
\text { et al. }{ }^{107}\end{array}$ \\
\hline
\end{tabular}

different types of Additive manufacturing machines. ${ }^{56,57}$

\section{4. $3 D$ printing}

It is used to create a 3D solid object from the 3D digital file by the addition of materials layer by layer which is formed under computer control. It is also used for concept generation and product development process. ${ }^{58,59}$ It produced 3D customised physical and anatomical shapes efficiently and used to manufacture complex geometrical shapes such as hanging partitions inside cavities. After taking scan data in STL format, the printing process takes an approximately maximum 4-6 hour. It has better fabrication speed with a lower cost of material. 3DP technology is a reliable method for reconstruction of precise bone and bone grafts, and it can also print full skill more quickly and cost-effectiveness as compared to other techniques. ${ }^{60,61}$ In medical education, there is a requirement of training. ${ }^{62,63}$ By using these $3 \mathrm{D}$ printing technologies, we print bio-models, implants, surgical aid tools, various scaffolds for tissue engineering and development of multiple medical devices, training models and repairing external organs such as skin.

\subsection{Inspection, testing and analysis of $3 D$ printed model}

Printed model is tested for the required strength, accuracy and dimensions model and its perfectness for medical use. Inspection is essential for the actual implementation of the printed model. It ensures that model which is manufactured by 3D printing technology is as per required quality and strength, under a specific condition of the load and must be feasible \& reliable. ${ }^{9}$

\section{Contemporary criteria's of 3D scanners}

A 3D Scanning device is suitable for medical applications in current scenario and everyday practice. It can create an accurate model at low cost. The resultant 3D file of the object in the computer can be stored digitally; can be edited according to the required shape and dimensions. This 3D digital file data is finally printable through various 3D printing technologies. 3D scanners are potent tools that are used professionally in many other industries such as aeronautics, automotive, jewellery, animation movies and video games. It can scan both big and small objects; there are limitless possibilities for artists by implementing this technology. It can translate our fantastic ideas into reality. It enhances its applications in the movie industry and video game. Before the advent of 3D scanning visual effects are not possible. The primary criteria's of the 3D scanner as being used for medical applications are discussed in following Table 2.

3 D Scanners have excellent ability to capture accurate data from the outer surface and helps in the best fabrication of physical model and treatment when well integrated with additive manufacturing processes for printing/inspection. With time, it is becoming cost effective, manipulated merely with high flexibility with optimised time. ${ }^{75}$ In next section, we are discussing some advancement of 3D scanning in the medical field.

\section{Advancement in medical Field by using 3D scanning}

These technologies also explore an essential role in the application of reverse engineering, rapid tooling, E- manufacturing process, product design and development. This technology is especially helpful in research and design. Table 3 discusses various advancement in the medical field by using the 3D scanning.

The main reason for implementing 3D scanning in the medical field is that it captures exact data of the surface and can well be used for research and development purpose. It is fast, safe, handy and accurate that helps to improve, maximise efficiency for specialised machining technology. ${ }^{81}$ 3D scanning technologies are expected to capture a much larger share market due to its wide availability and ease of use. 3D scanning help in the design of human body metrics, body shape, size and skin area. One can thoroughly assess the swelling status of the body and visualise the state of health in the 3D digital model. It can also help in digitising human body shapes for medico-legal purposes. Next section we discuss the various applications areas of 3D scanning in the medical field.

\section{Identifying applications areas of 3D scanning in medical Field}

In physical appearance and medical practitioners, each person is unique, one can use this information to create patient's customised medical products. In dental, it is used for generating the design of making braces, retainers and mouth guards. For face application, it creates a fitted face mask for the treatment of burn victims, and in hands, it helps to create customised gloves for patients. It has various applications in other body parts by which customised prosthetics such as leg and back also designs by using this technology. There is an exclusive growth in the medical and dental field by use of $3 \mathrm{D}$ scanning industries. By using traditional measurement devices, it is not possible to measure organic shapes. One can quickly produce $3 \mathrm{D}$ models and deliver it to doctors, scientists, researchers, engineers and technologists. Table 4 shows various applications where $3 \mathrm{D}$ scanning can be used in the medical field.

The popularity of 3D scanners is growing in the medical field. This technology is nimble, showing enhanced performance in data acquisition, reverse engineering and communication. Medical industry can take extensive benefits through 3D scanning technologies. Scanned models can be fed smoothly into the 3D printing machine for the fabrication of physical 3D model. This data capturing and measurement is a sufficiently reliable method as it increases the effectual working of 
complex shape parts and replaced damaged or missing part easily. By the applications of 3D scanning, medical field's requirements are solved easily in an efficient manner related to customisation, complex model design in shorter time and help in epidemiology, diagnosis, treatment and monitoring.

\section{A significant contribution to the study}

3D Scanning can have extensive contributions in the area of medical sciences. From the designing to the actual implementation of the model (part), and is quite helpful for the patient and the doctors. Significant finding through this research article are listed as follows:

- 3D scanning is a support technology and has extensive compatibility with 3D printing technology. It is vital for medical field as it captures external measurement of the body in less time, cost and better manner.

- It contributes to the development of scanning the human being and highly helpful to check body status and health improvements. It provides complete information about the outer surface of the body whereas technologies like x-rays, Ultrasound, CT and MRI cannot provide information about the upper surface of the body.

- Applications of 3D scanning technologies show potential for various fields, and there can be continuous improvement in the publication of papers related 3D scanning. It has the diverse application, and most of the work is done in materials and manufacturing field.

- In Medical field, 3D scanning help to solve the primary requirement such as complexity, generation of data in less time and cost toward the creation of the model

- 3D scanning integrates with many aspects of treatment such as orthotics/prosthetics, craniofacial surgery, accurate prescription of medicines and medication of eating disorders. It has advancement in human body matrices, adequately convey information about the body shape, size and skin surface area.

- 3D scanning is accurate, flexible and manipulated merely with low operational cost. It is used for scanning of both small and big objects. In research and development process it is suitable and used for preclinical testing, medical training and physical education.

- For the applications of different medical practitioners, 3D scanners can generate repeatable results. It is easy to operate with basic training which helps in daily use. Normally negative casts or impressions of obtained patient's body measurements are obtained. These physical moulds require transportation from the clinic to the laboratory. By using 3D Scanning, the whole is done electronically so these measurements data of patients can send online to different locations.

- The 3D scanning technologies have broad applications in the dental sector, like designing of teeth guards, metal braces and retainer. It is also used for making specially designed facemasks for different treating.

- 3D scanners are used in various universities, college and laboratories which allow researchers and students to study the artefacts in detail without any damage to the originals.

\section{Limitations and future scope}

3D scanning technologies only provide measurement and information of an outer part of the surface. It cannot scan beyond the surface level as in the case of CT, ultrasound and MRI, which provide internal information of the human body but are not able to scan the texture and colour and surface of the human body. Thus, $3 \mathrm{D}$ scanning is complementary to the contemporary scanning technologies, and for complete information, we need both types of scanning technologies.

However, 3D scanning cannot correctly undertake the scanning of transparent or reflective objects. Future scopes of 3D scanning technologies are for medical training, teaching, volume and flow measurements, digitisation and medico-legal purposes, clinical research and clinic-pathological correlation. This technology can be well coupled with holographic technology and virtual reality technology. Thus doctor can see the patients through holographic images, and Virtual reality can help in teaching purposes and improve communication between doctor and the patient. In future for mechanical engineering, 3D scanning technologies are to be widely used for inspection of the workpiece, reverse engineering, deformation analysis, general quality control procedures and re-engineering of moulds and die. In the civil engineering field, 3D scanning is used for building inspection, cultural heritage protection, furniture design, renovation, data prevention, CGI effect creation in movies industry. In architecture, it is used for modelling of building and its visualisation, partial modification visualisation for designing of buildings, reconstruction of creating historical building virtual models, historical object digitalisation. This technology is used in art reconstruction of historical and cultural monuments, such as the creation of the foundation for replicas and statues.

\section{Conclusion}

3D Scanners have become a potentially complementary scanning tool with other scanning technologies being used in the medical area. Researchers \& technologists can take advantages of improving the existing medical applications with 3D scanning technology; it can integrate research and surgical/ clinical practices holistically. 3D Scanning can be useful for the designing of surgical guides, custom implants and anatomical models, orthopaedics, cranial surgery, maxillofacial surgery and spinal surgery. This paper analyses the requirements of 3D scanning in medical applications and this technology makes a significant effect on a variety of medical applications. Models which are scanned by this technology can have improved quality of preoperative planning/diagnosis with enhanced team communication and assist the patients to understand their pathology better. By the application of this technology, one can contribute to designing and development of medical tooling and devices, prosthesis and orthotics, designing of mechanical bone replica, forensics, scaffolding and tissue engineering. It also helps to solve the problem faced by dentistry such as designing of dental models, customised bracket and archwires, removal appliances and occlusal splints. 3D scanning technologies design diverse medical model and tool according to requirement with a high level of precision. Effective utilisation of 3D scanners can be undertaken in complex cases, where we need customised treatment with quality. Thus there is extensive scope for research \& development.

\section{References}

1. Javaid M, Haleem A. Additive manufacturing applications in medical cases: a literature-based review. Alex J Med. 2017. http://dx.doi.org/10.1016/j.ajme.2017.09. 003.

2. Volonghi P, Baronio G, Signoroni A. 3D scanning and geometry processing techniques for customised hand orthotics: an experimental assessment. Virtual Phys Prototyp. 2018;13(2):105-116.

3. Jones PRM, Rioux M. Three-dimensional surface anthropometry: applications to the human body. Optics Lasers Eng. 1997;28(2):89-117.

4. Singh RP, Kataria R, Singhal S. Performance evaluation of macor dental ceramic: an investigation with rotary ultrasonic machining. Adv Dent Oral Health. 2018;8(2):555733. http://dx.doi.org/10.19080/ADOH.2018.08.555733.

5. Treleaven P, Wells J. 3D body scanning and healthcare applications. Computer. 2007;40(7):28-34

6. Willis A, Speicher J, Cooper DB. Rapid prototyping 3D objects from scanned measurement data. Image Vision Comput. 2007;25(1):1174-1184.

7. Bibb R, Eggbeer D, Evans P. Rapid prototyping technologies in soft tissue facial prosthetics: current state of the art. Rapid Prototyp J. 2010;16(2):130-137.

8. Carfagni M, Facchini F, Furferi R, et al. A semi-automatic computer-aided method for personalised vacuum bell design. Comput-Aided Des Appl. 2018;15(2):247-255.

9. Kumar L, Haleem A, Tanveer Q, Javaid M, Shuaib M, Kumar V. Rapid manufacturing: classification and recent development. Int J Adv Eng Res Sci. 2017;4(3):29-40.

10. Javaid M, Haleem A. Additive manufacturing applications in orthopaedics: a review. J Clin Orthop Trauma. 2018. http://dx.doi.org/10.1016/j.jcot.2018.04.008.

11. Straub J, Kerlin S. Development of a large, Low-cost, instant 3D scanner. 
Technologies. 2014;2(2):76-95.

12. Ross MT, Cruz R, Hutchinson C, Arnott WL, Woodruff MA, Powell SK. Aesthetic reconstruction of microtia: a review of current techniques and new 3Dprinting approaches. Virtual Phys Prototyp. 2018;13(2):117-130.

13. Ares M, Royo S, Vidal J, et al. 3D scanning system for in vivo imaging of human body. Berlin/Heidelberg, Germany: Springer; 2014:899-902.

14. Schievano S, Sebire NJ, Robertson NJ, Taylor AM, Thayyil S. Reconstruction of fetal and infant anatomy using rapid prototyping of post-mortem MR images. Insights Imaging. 2010;1(4):281-286.

15. Gapinski B, Wieczorowski M, Marciniak-Podsadna L, Dybala B, Ziolkowski G. Comparison of different method of measurement geometry using CMM, optical scanner and computed tomography 3D. Procedia Eng. 2014;69:255-262.

16. Daanen H, Hong SA. Made to measure pattern development based on 3D whole body scans. Int J Cloth Sci Technol. 2008;20(2):15-25.

17. Clark J. Features 3D scanning systems for rapid prototyping. Assem Autom 1997;17(3):206-210

18. Weckenmann A, Peggs G, Hoffmann J. Probing systems for dimensional micro- and nano-metrology. Meas Sci Technol. 2006;17(3):504-509.

19. Chromy A. Application of High-Resolution 3D scanning in medical volumetry. Int $J$ Electron Telecommun. 2016;62(1):23-31.

20. Singh RP, Singhal S. Investigation of machining characteristics in rotary ultrasonic machining of alumina ceramic. Mater Manuf Process. 2016;32(3):309-326.

21. D'Apuzzo N. 3D body scanning technology for fashion and apparel industry. Proceedings of IS\&T/SPIE Electronic Imaging 2007. 2007; 2007:6491.

22. Levine LE, Long GG. X-ray imaging with ultra-small-angle $\mathrm{X}$-ray scattering as a contrast mechanism. J Appl Crystallogr. 2004;37:757-765.

23. Han LH, Mapili G, Chen S, Roy K. Projection microfabrication of three-dimensional scaffolds for tissue engineering. J Manuf Sci Eng. 2008;130(2):1-4.

24. Singh RP, Singhal S. An experimental study on rotary ultrasonic machining of macor ceramic. Proc Inst Mech Eng Part B: J Eng Manuf. 2016. http://dx.doi.org/10.1177/ 0954405416666897.

25. Chromy A, Zalud L. Robotic 3D scanner as an alternative to standard modalities of medical imaging. Springerplus. 2014;3(1):1-10.

26. Tokkari N, Verdaasdonk RM, Liberton N, et al. Comparison and use of 3D scanners to improve the quantification of medical images (surface structures and volumes) during follow up of clinical (surgical) procedures. Progress in Biomedical Optics and Imaging Proceedings of SPIE. 2017; 2017

27. Zeng W, Lin F, Shi T, et al. Fused deposition modelling of an auricle framework for microtia reconstruction based on CT images. Rapid Prototyp J. 2008;14(5):280-284.

28. Chan AP, Fan J, Yu WM. Prediction of men's shirt pattern based on 3D body measurements. Int J Cloth Sci Technol. 2004;17(2):100-108.

29. Tawfik AM, Kerl JM, Razek AA, et al. Image quality and radiation dose of dualenergy CT of the head and neck compared with a standard 120-kVp acquisition. Am J Neuroradiol. 2011;32(11):1994-1999.

30. Swann S. Integration of MRI and stereolithography to build medical models: a case study. Rapid Prototyp J. 1996;2(4):41-46.

31. Thorhauer E, Miyawaki M, Illingworth K, Holmes JA, Anderst W. Accuracy of bone and cartilage models obtained from CT and MRI. In Poster Presented at the 34th Annual Meeting of the American Society of Biomechanics. 2010; 2010:18-21.

32. Vaezi M, Chua CK, Chou SM. Improving the process of making rapid prototyping models from medical ultrasound images. Rapid Prototyp J. 2012;18I(4):287-298.

33. Bye E, McKinney E. Fit analysis using live and 3D scan models. Int $J$ Cloth Sci Technol. 2010;22(2/3):88-100.

34. Choi JW, Wicker RB, Cho SH, Ha CS, Lee SH. Cure depth control for complex 3D microstructure fabrication in dynamic mask projection microstereolithography. Rapid Prototyp J. 2009;15(1):59-70.

35. Bo Q, Lichao Z, Yusheng S, Guocheng L. Support fast generation algorithm based on discrete-marking in stereolithography rapid prototyping. Rapid Prototyp J. 2011;17(6):451-457

36. Dawood A, Patel S, Brown J. Cone beam CT in dental practice. Br Dent J. 2009;207(1):23-28.

37. Javaid M, Kumar L, Kumar V, Haleem A. Product design and development using polyjet Rapid prototyping technology. Int J Control Theory Inform. 2015;5(3):12-19.

38. Cohen A, Laviv A, Berman P, Nashef R, Abu TJ. Mandibular reconstruction using stereolithographic 3-dimensional printing modeling technology. Oral surgery, Oral medicine, Oral pathology. Oral Radiol Endodontol. 2009;108(5):661-666.

39. Dahake SW, Kuthe AKM, Mawale MB, Bagde AD. Applications of medical rapid prototyping assisted customised surgical guides in complex surgeries. Rapid Prototyp J. 2016;22(6):934-946.

40. Sarghie B, Costea M, Liute D. Anthropometric study of the foot using 3D scanning method and statistical analysis. Proceedings of the International Symposium in Knitting and Apparel. 2013; 2013.

41. Singh RP, Singhal S. Rotary ultrasonic machining of macor ceramic: an experimental investigation and microstructure analysis. Mater Manuf Process. 2016;32(9):927-939.

42. Kumar L, Tanveer Q, Kumar V, Javaid M, Haleem A. Developing low cost 3 D printer. Int. J Appl Sci Eng Res. 2016;5(6):433-447.

43. Dai K, Shaw L. Distortion minimization of laser processed components through control of laser scanning patterns. Rapid Prototyp J. 2002;8(5):270-276.

44. Ciobanu O, Ciobanu G. The use of 3D scanning and rapid prototyping in medical engineering. Fiabil Durab. 2013;1:241-247.

45. Domanski J, Skalski K, Grygoruk R, Mróz A. Rapid prototyping in the intervertebral implant design process. Rapid Prototyp J. 2015;21(6):735-746.

46. Awasthi S, Pandey N. Rural background and low parental literacy associated with discharge against medical advice from a tertiary care government hospital in India. Clin Epidemiol Glob Health. 2015;3(1):24-28.
47. Dérand P, Rännar L, Hirsch J. Imaging, virtual planning, design, and production of patient-specific implants and clinical validation in craniomaxillofacial surgery. Craniomaxillofac Trauma Reconstruct. 2012;5(3):137-144.

48. Gibson I, Cheung LK, Chow SP, et al. The use of rapid prototyping to assist medical applications. Rapid Prototyp J. 2006;12(1):53-58.

49. Hsu S, Gateno J, Bell R, et al. Accuracy of a computer-aided surgical simulation protocol for orthognathic surgery: a prospective multicenter study. J Oral Maxillofac Surg. 2013;71(1):128-142.

50. Azari A, Nikzad S. The evolution of rapid prototyping in dentistry: a review. Rapid Prototyp J. 2009;15(3):216-225.

51. Barbero BR, Ureta ES. Comparative study of different digitisation techniques and their accuracy. Comput Aided Des. 2011;43(2):188-206.

52. Sitnik R, Michoński J, Glinkowski W. Supporting of postural deformities diagnosis using 3D scanning. Adv Int Syst Comput. 2018;635:269-280.

53. Drury JL, Mooney DJ. Hydrogels for tissue engineering: scaffold design variables and applications. Biomaterials. 2003;24(24):4337-4351.

54. Tukuru N, Gowda SKP, Ahmed SM, Badami S. Rapid prototype technique in medical field. Res J Pharm Technol. 2008;1(4):341-344.

55. Ebrahim MAB. 3D laser scanners' techniques overview. Int J Sci Res. 2015;4(10):323-331.

56. Dong Z, Jiang G, Wu Z, Cong H. 3D parametric human modeling for warp-knitted seamless garment. Int J Cloth Sci Technol. 2015;27(4):532-548.

57. Groenendyk M, Gallant R. 3D printing and scanning at the Dalhousie University Libraries: a pilot project. Libr Hi Tech. 2013;31(1):34-41.

58. Haleem A, Khan A, Javaid M. Design and development of smart landline using 3D printing technique. Int $J$ Adv Res Innov. 2016;4(2):438-447.

59. Singh RP, Singhal S. Experimental investigation of machining characteristics in rotary ultrasonic machining of quartz ceramic. Proc Inst Mech Eng Part L: J Mater Des Appl. 2016. http://dx.doi.org/10.1177/1464420716653422.

60. Kataria R, Singh RP, Kumar J. An experimental study on ultrasonic machining of tungsten carbide-cobalt composite materials. AIMS Mater Sci 2016;3(4):1391-1409.

61. Zhang G, Tsou Y, Rosenberger AL. Reconstruction of the Homunculus skull using a combined scanning and stereolithography process. Rapid Prototyp $J$. 2000;6:267-275.

62. Awasthi S. Biomedical publication - a neglected art in medical education in India. Clin Epidemiol Glob Health. 2013;5(1):3-4.

63. Lerch T, Anthony S, Domina T. Initial validation of point cloud data from a 3D body scanner. Int J Cloth Sci Technol. 2008;20(5):271-280.

64. Li P, Lee C, Corner B. Computing surface area and volume of parachutes from 3D scans. Eng Comput. 2005;22(4):393-408.

65. Javaid M, Haleem A. Current status and challenges of additive manufacturing in orthopaedics: an overview. J Clin Orthopaed Trauma. 2018 Accepted in May 2018

66. Paquette S. 3D scanning in apparel design and human engineering. IEEE Comput Graph Appl. 1996;16(5):11-15.

67. Hong SA, Daanen HAM. 3D scan related research in TNO and its application for apparel industry. Fashion Inf Technol. 2004;1:72-80.

68. Cynthia L, Hwang ISJ. 3D body scanning systems with application to the apparel industry. J Fashion Market Manag: Int J. 2001;5(2):120-132.

69. Lopes AJ, MacDonald E, Wicker RB. Integrating stereolithography and direct print technologies for 3D structural electronics fabrication. Rapid Prototyp $J$. 2012;18(2):129-143.

70. McKinnon L, Istook CL. Body scanning - the effects of subject respiration and foot positioning on the data integrity of scanned measurements. J Fashion Market Manag. 2002;6(2):103-121.

71. Salleh MNB, Acar M, Burns ND. Customised pressure garment development by using 3D scanned body image. Res J Textile Apparel. 2011;15(4):9-18.

72. Berger U. Aspects of accuracy and precision in the additive manufacturing of plastic gears. Virtual Phys Prototyp. 2015;10(2):49-57

73. Cho Y, Okada N, Park H, Takatera M, Inui S, Shimizu Y. An interactive body model for individual pattern making. Int J Cloth Sci Technol. 2005;17(2):91-99.

74. Izatt MT, Thorpe PL, Thompson RG, et al. The use of physical biomodelling in complex spinal surgery. Eur Spine J. 2007;16(9):1507-1518.

75. Singh RP, Singhal S. Rotary ultrasonic machining of alumina ceramic: experimental study and optimization of machining responses. J Eng Res. 2018;6(1):192-215.

76. Maher PS, Keatch RP, Donnelly K, Mackay RE, Paxton JZ. Construction of 3D biological matrices using rapid prototyping technology. Rapid Prototyp J. 2009;15(3):204-210.

77. Yap YL, Tan YSE, Tan HKJ, et al. 3D printed bio-models for medical applications. Rapid Prototyp J. 2017;23(2):227-235.

78. Liu K, Wang Y, Lau DL, Hao Q, Hassebrook LG. Dual-frequency pattern scheme for high-speed 3-d shape measurement. Opt Express. 2010;18(5):5229-5244.

79. Kashani J, Arabshahi Z, Kadir M, Azari A. Manufacturing of flexible surgical guide for fully edentulous patients. Adv Mater Res. 2012;488:1001-1005.

80. Hong Y, Bruniaux P, Zeng X, Liu K, Chen Y, Dong M. Virtual reality-based collaborative design method for designing customized garment for disabled people with scoliosis. Int J Cloth Sci Technol. 2017;29(2):226-237.

81. Singh RP, Singhal S. Rotary ultrasonic machining: a review. Mater Manuf Process. 2016;31(14):1795-1824.

82. Parthasarathy J. 3D modeling, custom implants and its future perspectives in craniofacial surgery. Ann Maxillofac Surg. 2014;4(1):9-18.

83. Shahbazian M, Jacobs R, Wyatt J, et al. Accuracy and surgical feasibility of a CBCTbased stereolithographic surgical guide aiding autotransplantation of teeth: in vitro validation. J Oral Rehabil. 2010;37(11):854-859

84. Singh RP, Singhal S. Experimental study on rotary ultrasonic machining of alumina ceramic: microstructure analysis and multi-response optimization. Proceed Inst Mech 
Eng Part L: J Mater Des Appl. 2016. http://dx.doi.org/10.1177/1464420716657370.

85. Jardini AL, Larosa MA, Zavaglia CAC, et al. Customised titanium implant fabricated in additive manufacturing for craniomaxillofacial surgery. Virtual Phys Prototyp. 2014;9(2):115-125.

86. Markl M, Schumacher R, Küffer J, Bley TA, Hennig J. Rapid vessel prototyping: vascular modeling using $3 \mathrm{t}$ magnetic resonance angiography and rapid prototyping technology. Magn Reson Mater Phys Biol Med. 2005;18(6):288-292.

87. Elsheikh A, Wang D, Pye D. Determination of the modulus of elasticity of the human cornea. J Refract Surg. 2007;23(8):808-818.

88. Hin AJS, Krul AJ. Performance of human solutions body dimensions software. Report 2005-A9, TNO human factors. 2005; 2005 Soesterberg.

89. Zein NN, Hanouneh IA, Bishop PD, et al. Three-dimensional print of a liver for preoperative planning in living donor liver transplantation. Liver Transplant. 2013;19(12):1304-1310

90. Lienau J, Schell H, Duda GN, Seebeck P, Muchow S, Bail HJ. Initial vascularization and tissue differentiation are influenced by fixation stability. $J$ Orthopaed Res. 2005;23(3):639-645

91. Ludlow JB, Ivanovic M. Comparative dosimetry of dental CBCT devices and 64-slice CT for oral and maxillofacial radiology. Oral surgery, Oral medicine, Oral pathology. Oral Radiol Endodontol. 2008;106(1):106-114.

92. Shiraishi I, Yamagishi M, Hamaoka K, Fukuzawa M, Yagihara T. Simulative operation on congenital heart disease using rubber-like urethane stereolithographic biomodels based on 3D datasets of multislice computed tomography. Eur J Cardio Thorac. 2010;37(2):302-306.

93. Waran V, Narayanan V, Karuppiah R, Owen SL, Aziz T. Utility of multi-material 3D printers in creating models with pathological entities to enhance the training experience of neurosurgeons. J Neurosurg. 2014:120(2):489-992.

94. Awasthi S, Verma T, Agarwal M, Singh JV, Srivastava NM, Nichterd M. Developing effective health communication messages for community acquired pneumonia in children under five years of age: a rural North Indian qualitative study. Clin Epidemiol Glob Health. 2017;5(3):107-116.

95. Konrad P, Neimat J, Yu H, et al. Customized, miniature rapid prototype stereotactic frames for use in deep brain stimulator surgery: initial clinical methodology and experience from 263 patients from 2002 to 2008. Stereotact Funct Neurosurg. 2011;89(1):34-41.
96. Singh RP, Singhal S. Rotary ultrasonic machining of advanced materials: a review. Int J Technol Res Eng. 2015;2(7):777-785.

97. Wang J, Gallagher D, Thornton JC, Yu W, Horlick M, Pi-Sunyer FX. Validation of 3-dimensional photonic scanner for the measurement of body volumes, dimensions, and percentage body fat. Am J Clin Nutr. 2006;83(4):809-816.

98. Koivisto J, Wolff J, Jarnstedt J, Dastidar P, Kortesniemi M. Assessment of the effective dose in supine, prone, and oblique positions in the maxillofacial region using a novel combined extremity and maxillofacial cone beam computed tomography scanner. Oral Surg Oral Med Oral Pathol Oral Radiol. 2014;118(3):355-362.

99. Liang X, Lambrichts I, Sun Y, et al. A comparative evaluation of cone beam computed tomography (CBCT) and multi-slice CT (MSCT). Part II: on 3D model accuracy. Eur J Radiol. 2010;75(2):270-274

100. Kerens B, Boonen B, Schotanus M, Kort N. Patient-specific guide for revision of medial unicondylar knee arthroplasty to total knee arthroplasty: beneficial first results of a new operating technique performed on 10 patients. Acta Orthopaed. 2013;84(2):165-169.

101. Yang C, Tian X, Liu T, Cao Y, Li D. 3D printing for continuous fiber reinforced thermoplastic composites: mechanism and performance. Rapid Prototyp $J$. 2017;23(1):209-215

102. Singh RP, Kumar J, Kataria R, Singhal S. Investigation of the machinability of commercially pure titanium in ultrasonic machining using graph theory and matrix method. J Eng Res. 2015;3(4):75-94.

103. Horiguchi C. BL (body line) scanner - the development of a new 3-D measurement and reconstruction system. Int Arch Photogram Remote Sens. 1998;32(5):421-429.

104. Wells JCK, Douros I, Fuller NJ, Elia M, Dekker L. Assessment of body volume using a near infra-red 3-D photographic scanner. Ann NY Acad Sci. 2000;904:247-254.

105. Negi S, Dhiman S, Sharma RK. Basics and applications of rapid prototyping medical models. Rapid Prototyp J. 2014;20(3):256-267.

106. Ventura ACS, Böhnke M, Mojon DS. Central corneal thickness measurements in patients with normal tension glaucoma, primary open angle glaucoma, pseudoexfoliation glaucoma, or ocular hypertension. Br J Ophthalmol. 2001;85(7):792-795

107. Landers R, Hubner U, Schmelzeisen R, Mulhaupt R. Rapid prototyping of scaffolds derived from thermoreversible hydrogels and tailored for applications in tissue engineering. Biomaterials. 2002;23(23):4437-4447. 